\title{
Relations between upper abdominal symptoms and gastric distension abnormalities in dysmotility like functional dyspepsia and after vagotomy
}

\author{
L E A Troncon, D G Thompson, N K Ahluwalia, J Barlow, L Heggie
}

\begin{abstract}
Postprandial bloating and fullness are commonly found both in dysmotility like functional dyspepsia, and after vagotomy but the relation between gastric accommodation and symptom production has not been investigated. Intragastric pressure levels and symptoms developed during controlled distension of the gastric fundus were recorded in nine patients with functional dyspepsia, in seven patients after truncal vagotomy, and in 11 healthy volunteers. The procedure was repeated after ingestion of a liquid nutrient meal (250 ml; $250 \mathrm{kcal})$. Gastric tone, expressed as the average value of pressure over the distension period was lower in controls (median: $11.3 \mathrm{~mm} \mathrm{Hg}$ ) than in either the dyspeptic patients (median: $16.48 \mathrm{~mm} \mathrm{Hg}$ ) or postvagotomy patients (median: $19 \cdot 12 \mathrm{~mm} \mathrm{Hg})(p<0 \cdot 05)$. Meal ingestion reduced gastric tone in controls, but no significant change occurred in either the dyspepsia or the postvagotomy patients. Volumes at which discomfort was elicited by distension during fasting were lower both in dyspeptic patients (median: $210 \mathrm{ml}$ ) and in postvagotomy patients (median: $180 \mathrm{ml}$ ) than in healthy volunteers (median: 660 ml) $(\mathbf{p}<0 \cdot 05)$. Discomfort thresholds were unaffected by meal ingestion. These results suggest that a disturbance of gastric relaxation may be related to symptom development in dysmotility like functional dyspepsia, while similarities between dyspeptic patients and postvagotomy patients suggest that the impaired gastric accommodation in functional dyspepsia may be due to an underlying vagal defect.

(Gut 1995; 37: 17-22)
\end{abstract}

Keywords: gastric distension, dyspepsia, vagotomy, postprandial bloating.

Department of Medicine, University of Manchester Medical School, Hope Hospital, Salford

L E A Troncon

D G Thompson

N K Ahluwalia

J Barlow

L Heggie

Correspondence to: Dr D G Thompson Department of Medicine, Hope Hospital, Eccles Old Road, Salford M6 8HD.

Accepted for publication 1 November 1994

Functional dyspepsia, also known as chronic idiopathic dyspepsia, is a common condition defined by upper abdominal symptoms that are not explained by any structural abnormality on conventional investigation. ${ }^{1}$ Functional dyspepsia is now conventionally subdivided into ulcer like, reflux like, and dysmotility like groups ${ }^{2}$ according to symptoms experienced. Symptoms in patients with dysmotility like dyspepsia include epigastric discomfort or pain, upper abdominal bloating, early satiety, belching, nausea, and vomiting. ${ }^{2}$ These symptoms often occur in clusters and are characteristically associated with food ingestion.

Several studies have suggested an association between the symptoms of dysmotility like dyspepsia and abnormalities of upper gastrointestinal motility, including abnormal gastric myoelectric activity, ${ }^{3}$ antral dysmotility, ${ }^{4}$ delayed gastric emptying, ${ }^{45}$ and disturbances of duodenal and jejunal motor activity. ${ }^{67}$ Nevertheless, these dysfunctions cannot fully explain the symptoms, because almost half the patients show no detectable abnormality of gastric manometric activity or gastric emptying $^{8}$ and no correlation exists between symptom severity and those functional abnormalities that are found. 59

A similar symptom pattern to that characterising dysmotility like dyspepsia (particularly postprandial bloating), is commonly found in patients after bilateral truncal vagotomy ${ }^{10}$ in whom defective relaxation of the gastric fundus occurs in response to distension. ${ }^{11}$ This similarity of symptom character, raises the possibility that a disturbance of the gastric accommodation process in response to food, might be common to the two conditions.

In a previous study ${ }^{12}$ we assessed gastric accommodation mechanisms in normal subjects by determining intragastric pressurevolume relations during controlled gastric distension, both under fasting conditions and after meal ingestion, and showed that food increased gastric accommodation.

In this paper, we report a study designed to compare the relations between symptoms and gastric responses to distension, in patients with dysmotility like functional dyspepsia and in patients with similar upper abdominal symptoms after bilateral truncal vagotomy.

\section{Methods}

SUBJECTS
Nine patients with dysmotility like functiona tomy patients (six male and one female; median age: 45 years; range: 31-74), and 11 healthy asymptomatic volunteers (six male and five female; median age: 25 years; range: 22-44) participated in the study after giving informed consent. The protocol for the study had been previously approved by the Salford Health Authority ethics committee. dyspepsia (five male and four female; median 
Functional dyspepsia patients

All the patients with functional dyspepsia had been referred to our centre because of chronic, severe, upper abdominal symptoms, particularly bloating, related to meals. All had suffered from their symptoms for at least one year and regarded themselves as being seriously disabled. None had evidence of a peptic ulcer, previous gastric surgery or any systemic disease known to affect gastrointestinal motility. Common laboratory tests, upper digestive tract endoscopy, barium meal examination, and abdominal ultrasonography were normal in all.

\section{Postvagotomy patients}

All postvagotomy patients had been referred for assessment of postprandial symptoms. All had been submitted to bilateral truncal vagotomy and pyloroplasty for peptic ulcer three to 18 years (median: 10 years) before the study. All suffered from severe postprandial bloating, which had started soon after the surgery and which had caused them to reduce the size of their meals. In addition, three had dumping syndrome and three others had postprandial diarrhoea.

All drugs were stopped for at least 72 hours before the study in all patients.

\section{Healthy volunteers}

Volunteers were recruited from the medical personnel and student population of the University of Manchester. All were symptom free at the time of study and none gave a history of either digestive tract or systemic disease, or previous abdominal surgery.

\section{STUDY DESIGN}

Gastric accommodation was assessed both during fasting and after the ingestion of a standard meal, by serial measurement of intragastric pressure during stepwise fundal distension using an ultrathin polyethylene bag (capacity $1200 \mathrm{ml}$ ), mounted on a 14 French gauge polyvinyl catheter (RT $20 \mathrm{~N}$, Pennine Health Care Products, Derby, UK). Details of the methodology have been previously published. ${ }^{12}$ The catheter bag assembly was introduced through the mouth into the gastric fundus and the proximal end of the catheter was connected to a strain gauge transducer calibrated against a commercial electronic digital manometer (DPI 700, Druck, Grosby, Leicestershire, UK), capable of measuring intrabag pressure in the range 0 to $64 \mathrm{~mm} \mathrm{Hg}$ with a maximum inherent error of $0.25 \mathrm{~mm} \mathrm{Hg}$. At each distension volume, a series of 12 consecutive readings of intrabag pressure were taken at five second intervals and averaged to give a mean value for intragastric pressure. Inflation of the bag in the air showed no increase in intrabag pressure until at least $1200 \mathrm{ml}$ was introduced.

\section{PROTOCOL}

Bag insertion

All subjects were studied in the morning after an overnight fast while reclining comfortably in a semirecumbent position in a quiet room. Firstly, the bag was folded upon the gastric tube, swallowed, and advanced until sited in the body of the stomach. The bag was then unfolded by inflation with $400 \mathrm{ml}$ of air and the tube was gently withdrawn until resistance of the bag against the lower oesophageal sphincter was felt. The catheter was then reinserted $2 \mathrm{~cm}$ to ensure that the proximal end of the bag was clear of the gastrooesophageal junction, the bag fully deflated, and the catheter fixed to the cheek with adhesive tape.

\section{Fasting inflations}

After a 10 minute rest period, the bag was progressively inflated in $30 \mathrm{ml}$ increments at one minute intervals until the maximal tolerated volume was reached.

In previous studies with this technique it was found that the first distension of the stomach induced a variable degree of gastric relaxation, after which the pressure-volume relations remained constant during all subsequent fasting distensions. ${ }^{12}$ In this study, therefore, a second inflation was performed immediately after the first, and the data from this second inflation were used to construct the fasting gastric pressure-volume curve.

\section{Post-meal inflation}

At the end of the fasting study, the bag was deflated and the subject was allowed to rest for 10 minutes before drinking $250 \mathrm{ml}$ of a liquid mixed nutrient meal (Fortison, Cow and Gate, Trowbridge, composition: $1.0 \mathrm{kcal} / \mathrm{ml}$; carbohydrate: $12 \cdot 0 \%$; protein: $4.0 \%$; lipid: $4 \cdot 0 \%$ ). Five minutes after the end of meal ingestion, another graded gastric distension was performed to the maximal tolerated volume.

\section{ASSESSMENT OF SENSATIONS ELICITED BY} GASTRIC DISTENSION

At every $150 \mathrm{ml}$ of gastric distension, subjects were asked to report their sensations. Subjects were specifically instructed to report the first time they felt uncomfortable. Gastric distension was stopped at the maximally tolerated volume, which corresponded either to the sensation of painful discomfort or to the development of nausea. Throughout the study, the subjects were kept unaware of the volume in the bag.

\section{DATA ANALYSIS}

Pressures recorded during each distension were plotted against the corresponding bag volumes for each subject studied. From these intragastric pressure-volume curves the following parameters were derived.

Gastric tone = an index of tone was obtained by adding all the values of intragastric pressure obtained from the inflations between $30 \mathrm{ml}$ to the maximally tolerated volume and dividing this value by the number of inflation steps. 
Figure 1: Pressure-volume relations (median values) for three series of controlled gastric distension $\mathrm{O}=$ first, fasting, $\mathbf{\Delta}=$ second, fasting, and $=$ third, after $a$ meal) in 11 control subjects, nine dysmotility like functional dyspeptic patients, and seven postvagotomy patients.
Figure 2: Individual values of intragastric pressure during gastric distension in fasting conditions and after meal ingestion in 11 control subjects, nine dysmotility like functional dyspeptic patients, and seven postvagotomy patients.

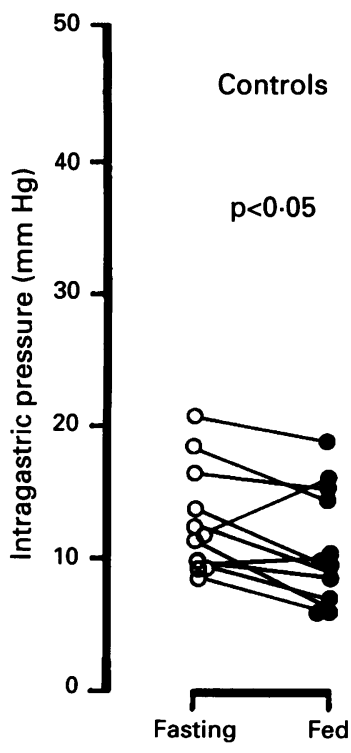

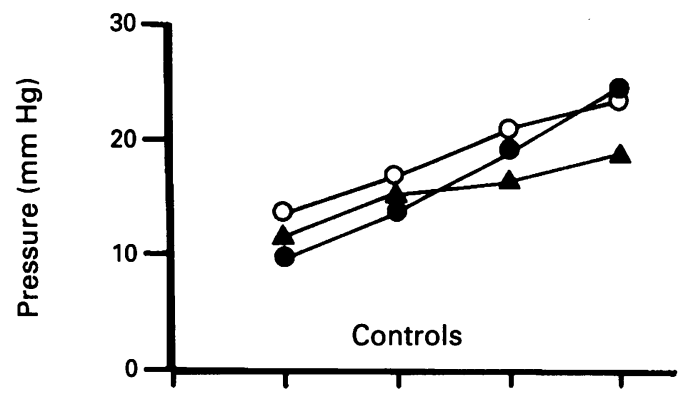
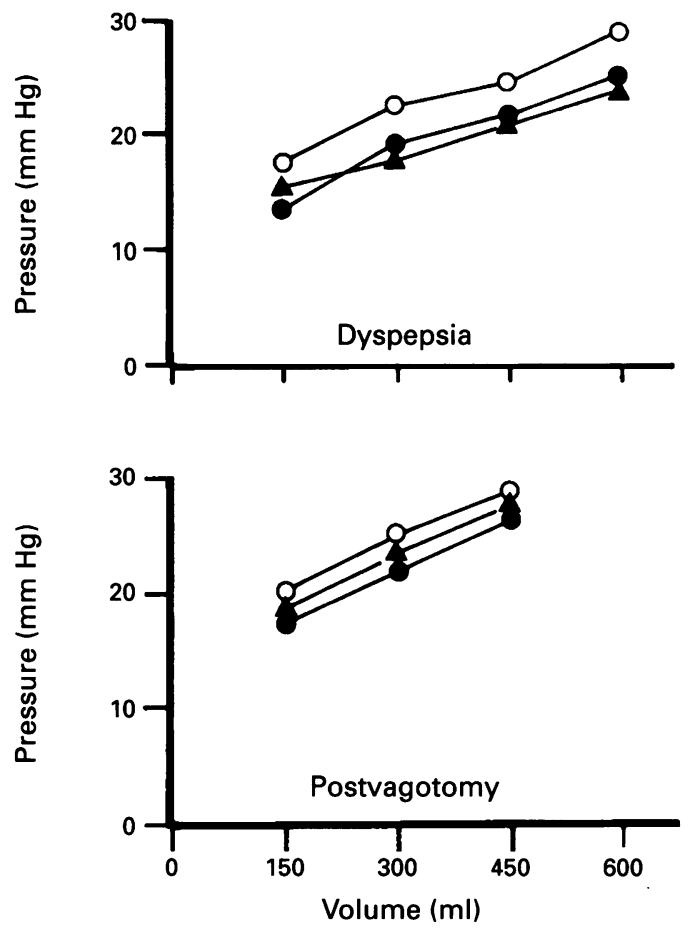

Gastric stiffness - as in previous studies ${ }^{12}$ this was defined as the slope of the log transformed intragastric pressure-volume curves, calculated by linear regression. For convenience, values are presented $\times 10^{5}$.

Gastric sensation - to assess the sensations elicited by distension the following parameters were defined.

Dyspepsia

Postvagotomy

$p>0.10$

$p>0 \cdot 10$
Volume at the onset of discomfort - the volume of inflation at which the sensation of discomfort was first reported.

Pressure at the onset of discomfort - the intragastric pressure recorded at the onset of discomfort.

Maximal tolerated volume - the volume of inflation at which distension was stopped.

Pressure at the limit of tolerance - the intragastric pressure recorded at the maximal tolerated volume.

\section{STATISTICAL ANALYSIS}

To avoid the assumption of a normal distribution of the data, the results are expressed as median and range of distribution. Nonparametric tests were used for the statistical analysis $^{13}$; for comparisons between the three groups we used the Mann-Whitney $U$ test. Paired data regarding fasting versus fed results were analysed by the Wilcoxon's signed rank matched paired test. Differences were taken to be biologically relevant for values of $p$ of less than $0 \cdot 05$.

\section{Results}

PRESSURE:VOLUME CHARACTERISTICS

Figure 1 shows the intragastric pressure volume relations during the three gastric distensions in the three groups of subjects.

\section{Fasting studies}

Gastric tone - Fig 2 presents the data for the three subject groups. Values for controls ranged from 8.0 to $20.6 \mathrm{~mm} \mathrm{Hg}$ (median: 11.3 $\mathrm{mm} \mathrm{Hg}$ ) and were significantly lower than those for either the functional dyspepsia patients or the postvagotomy patients. Values obtained in dyspeptic patients and postvagotomy patients were similar, however $(p<0 \cdot 20)$.

Gastric stiffness - data for the slopes of the intragastric pressure-volume curves ranged from $43-115 \mathrm{~mm} \mathrm{Hg} / 30 \mathrm{ml}$ in controls (median: $78 \mathrm{~mm} \mathrm{Hg} / 30 \mathrm{ml}$ ). Values obtained in functional dyspepsia patients (median: 75 $\mathrm{mm} \mathrm{Hg} / 30 \mathrm{ml}$; range: $41-192 \mathrm{~mm} \mathrm{Hg} / 30 \mathrm{ml}$ ) were similar $(p>0 \cdot 10)$. In the postvagotomy group, values ranged $46-113 \mathrm{~mm} \mathrm{Hg} / 30 \mathrm{ml}$ (median: $60.5 \mathrm{~mm} \mathrm{Hg} / 30 \mathrm{ml}$ ) and were again similar to both the control and dyspeptic groups $(p>0 \cdot 05)$.

\section{After meal}

Gastric tone - data are again shown in Fig 2. In the control group, postprandial gastric tone was lower than during fasting. In contrast, no consistent reduction in tone occurred in either the functional dyspepsia, or the postvagotomy, patients $(\mathrm{p}>0 \cdot 10)$.

Gastric stiffness - was reduced by food in control subjects. Slope values ranged from 28.0 to $92.2 \mathrm{~mm} \mathrm{Hg} / 30 \mathrm{ml}$ (median: $60.2 \mathrm{~mm}$ $\mathrm{Hg} / 30 \mathrm{ml}$ ) and were consistently lower than in those found during fasting $(p<0.05)$. In functional dyspepsia patients, slope values 

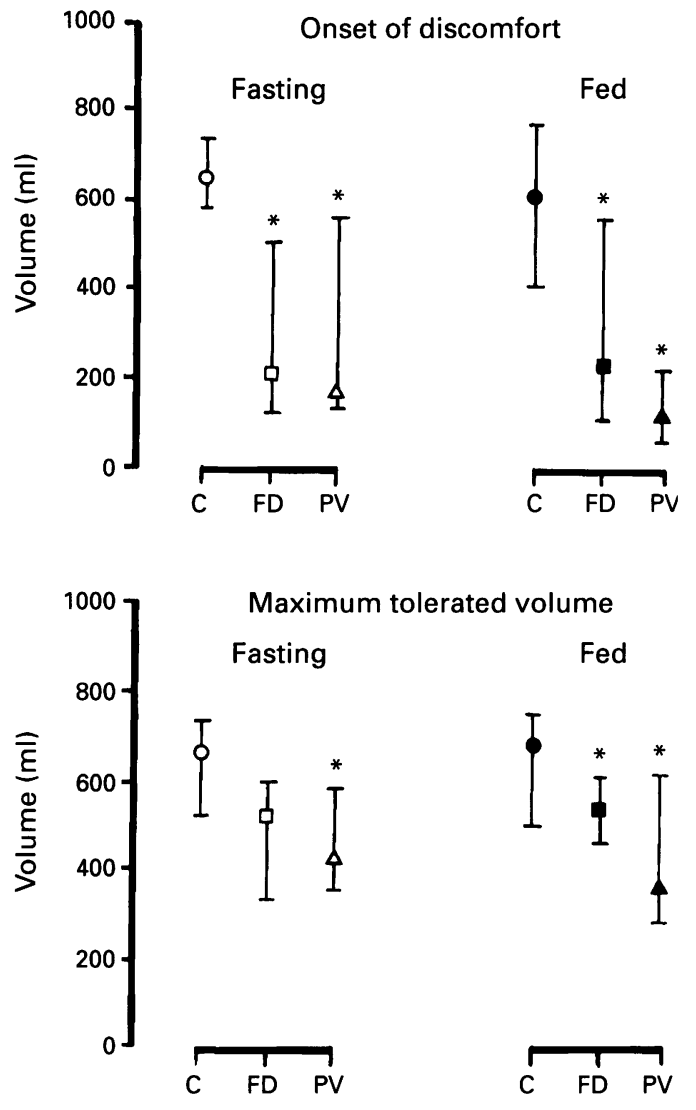

${ }^{*} \mathrm{p}<0.05 v$ controls

Figure 3: Volume (median and interquartile interval) within the intragastric bag at the onset of, and at the maximal tolerated, discomfort in fasting conditions and after meal ingestion in 11 control subjects $(C)$, nine dysmotility like functional dyspeptic patients (FD), and seven postvagotomy patients (PV).

were also reduced by meal ingestion, with postprandial values (median: $43.5 \mathrm{~mm} \mathrm{Hg} / 30$ $\mathrm{ml}$; range: $21 \cdot 0-114.0 \mathrm{~mm} \mathrm{Hg} / 30 \mathrm{ml}$ ), which were lower than fasting values $(p<0.05)$. In contrast, postvagotomy patients showed no change in stiffness after meal ingestion, slope values (median: $64.0 \mathrm{~mm} \mathrm{Hg} / 30 \mathrm{ml}$; range: $30.0-16.0 \mathrm{~mm} \mathrm{Hg} / 30 \mathrm{ml}$ ) remaining similar to those recorded during fasting $(p>0 \cdot 05)$.

\section{SENSORY RESPONSES TO DISTENSION}

\section{Fasting}

Volume at onset of discomfort - in the control group, the inflation volume at the onset of discomfort was $660 \mathrm{ml}$ (median) (range 510-990). Discomfort was elicited at lower volumes both in the dyspeptic patients (median: $210 \mathrm{ml}$ ) and in the postvagotomy group (median: $180 \mathrm{ml})(\mathrm{p}<0.05)($ Fig 3$)$.

Pressure at onset of discomfort - the pressure within the bag at the onset of discomfort was similar in all three subject groups (Fig 4).

Maximum tolerated volume - was similar in controls (660 ml (range: 540-900)), and in dyspeptic patients (median: $525 \mathrm{ml}$; range: $390-750)$, but both were higher $(p<0.02)$ than in postvagotomy patients (median: $440 \mathrm{ml}$; range: $210-660$ ) (Fig 3).

Pressure at the limit of tolerance - was similar in all groups (Fig 4).
After meal

Volume at onset of discomfort - the volume at which discomfort was first reported in the normal subjects (median: $615 \mathrm{ml}$; range 330-850) was similar to fasting values (Fig 3). In the functional dyspepsia group, volumes (median: $240 \mathrm{ml}$; range: 120-660) were also similar to fasting and were again consistently lower $(p<0.05)$ than those recorded in the normal subjects. Values in the postvagotomy patients were also similar to fasting and lower $(p<0.05)$ than those seen in the normal subjects.

Pressure at the onset of discomfort - was reduced by meal ingestion (Fig 4) in the control subjects and the functional dyspepsia group. In contrast, values were not different from fasting (median: $17.9 \mathrm{~mm} \mathrm{Hg}$; range: $10 \cdot 6-21 \cdot 7)$ in the postvagotomy group.

Maximum tolerated volume and pressure neither the maximum tolerated distension volumes nor the pressures were changed by food in any of the groups studied.

\section{Discussion}

The results of this study show that patients with dysmotility like functional dyspepsia show abnormally raised proximal gastric tone after meal ingestion, and an increased sensitivity to distension, suggesting that a disturbance in gastric relaxation may be related to the symptoms.

Gastric relaxation is a property of the proximal stomach in response both to distension and to nutrient ingestion, ${ }^{14}$ mediated at least in part by an inhibitory non-adrenergic, non-cholinergic vagal pathway. ${ }^{14} 15$

While an impairment in gastric relaxation after food has previously been suspected to be associated with postprandial symptoms in patients with functional dyspepsia, ${ }^{1}$ three recent studies aiming at assessing intragastric pressure-volume relations in dyspeptic patients have failed to show any abnormality. ${ }^{16-18}$ It does not seem that methodological differences could account for the discrepancy between these previously reported results and our own data because the techniques used for assessing pressure-volume relations seem to be similar in all studies. The most probable explanation therefore seems to lie in patient selection, we studied a more homogeneous subgroup of dyspeptic patients, including only those with dysmotility like symptoms and excluding those with other dyspeptic symptom patterns, which were included by others and which might have reduced the possibility of showing an abnormality.

After bilateral truncal vagotomy in dogs, an impaired gastric relaxatory response to intraintestinal nutrient ${ }^{15}$ and to feeding ${ }^{19}$ has been seen, showing that the relaxation is vagally mediated. Our study seems now to confirm this abnormality in humans. It is of further interest to note that the abnormalities in the dyspeptic patients resemble closely those found in postvagotomy patients suggesting perhaps a common aetiology for the development of symptoms in the two conditions. Our 

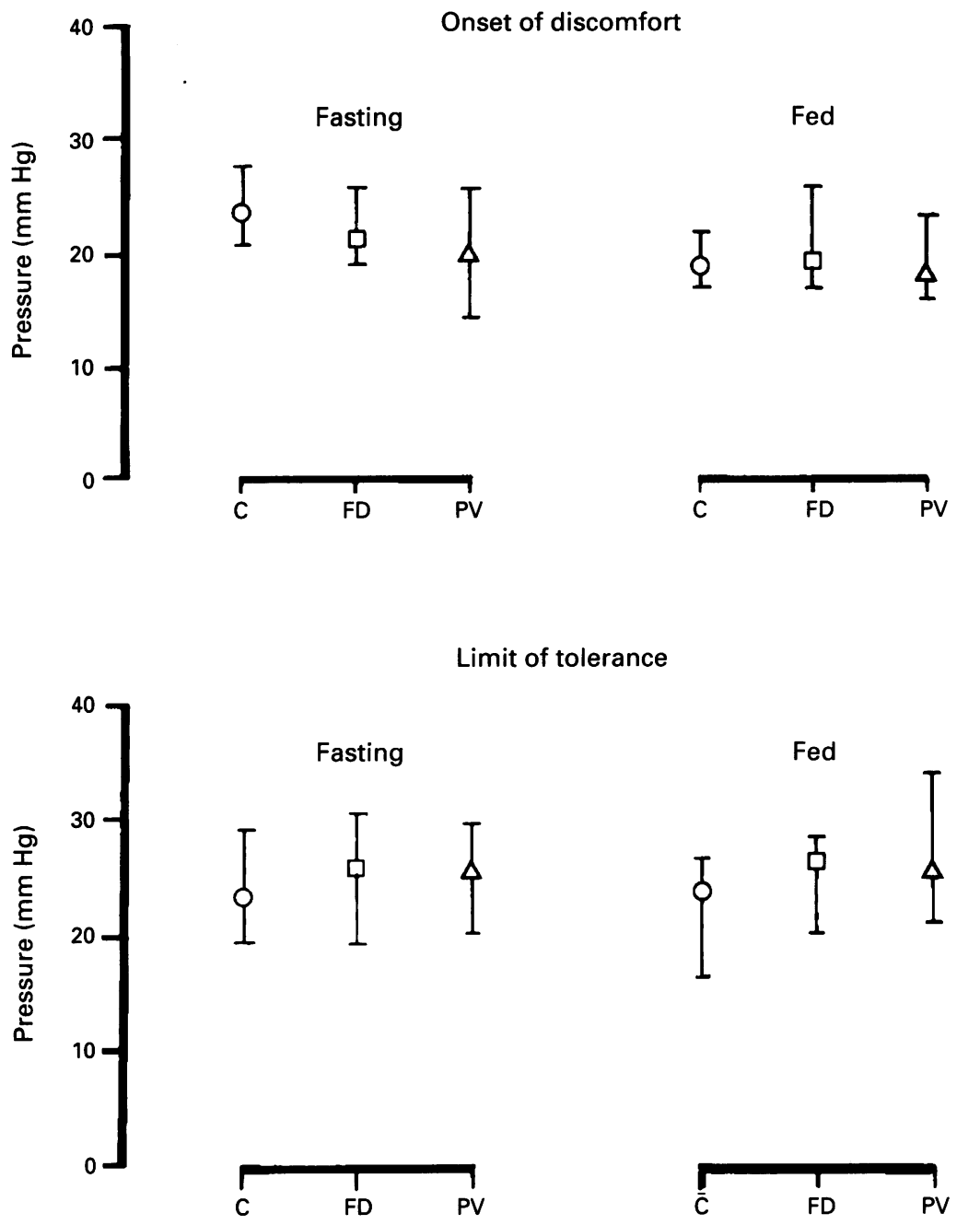

Figure 4: Pressure (median and interquartile interval) within intragastric bag at the onset of, and at the maximal tolerated, discomfort during fasting and after meal ingestion in 11 control subjects, nine dysmotility like functional dyspeptic patients, and seven postvagotomy patients. Abbreviations as in Fig 3.

work thus not only supports the concept that, in humans, intact vagal pathways are of major importance in the mediation of gastric relaxatory response to distension and to food, but also suggests that a neural defect may participate in the production of gastric tone abnormalities in functional dyspepsia although it remains uncertain where precisely in the pathway such a defect might occur.

Our method of estimating gastric tone by averaging intragastric pressures measured during distension probably includes components of both basal tone and the relaxatory response to distension. In the fasted state, gastric tone seems to be the consequence of a balance between excitatory cholinergic ${ }^{14}$ and non-adrenergic, non-cholinergic inhibitory vagal efferents, the second entailing nitric oxide release. ${ }^{20}$

It seems unlikely that the increased fasting gastric tone in dyspeptic patients is caused by cholinergic hyperactivity because measurements of vagally mediated gastric acid secretion $^{21}$ and pancreatic polypeptide release ${ }^{22}$ in functional dyspepsia are normal. It seems more probable therefore that the increased fasting tone is the result of defective neural inhibitory pathways. These defects do not necessarily imply damage to the vagus nerve trunks, however, as the destruction of intramural ganglia and intrinsic nerve fibres of the stomach also impairs gastric accommodation to a similar degree to vagotomy. ${ }^{23}$

The postvagotomy patients, showed normal gastric wall stiffness in the fasted state, but, unlike controls and dyspeptic patients, failed to show a reduction in stiffness after meal ingestion. This is unlikely to be explained simply by an abnormality of the passive viscoelastic properties of the stomach, which it has been suggested, exists after vagotomy, ${ }^{24}$ as gastric stiffness reflects more than the passive elastic characteristics of the stomach, being changed by meal ingestion ${ }^{12}$ as well as by intragastric lipids and osmolytes. ${ }^{25}$

Both the dyspepsia and postvagotomy patients reported the onset of discomfort at an abnormally low volume both under fasting conditions and after meal ingestion although it is important to note that the intragastric pressure at which discomfort was triggered was similar to that in the normal subjects. Previous experimental work in humans ${ }^{26}$ has suggested that epigastric fullness and abdominal discomfort may be elicited either by excessive distension of a relaxed stomach or by the development of increased gastric muscle tone. As intramural tension can be expressed as a function of both gastric wall stretch (which is related to intragastric volume) and gastric tone (which is related to intragastric pressure), ${ }^{12}$ it follows that if intragastric pressure is similar, and the volume is less, then the discomfort must be the result of either changed mechanoreceptor sensitivity or increased tone in the gastric wall. As our data show that in the fasted stomach tone is increased in both patient groups studied, this seems to be the most plausible explanation for the increased discomfort and is thus consistent with the view that a failure of the stomach to relax in response to meal ingestion is the cause of postprandial bloating, not only in postvagotomy patients but also in dysmotility like dyspepsia.

After vagotomy, defective postprandial gastric relaxatory responses and increased intragastric pressure probably contribute to the accelerated initial phase of gastric emptying known to occur in the condition. ${ }^{27}$ This contrasts, however, with the reports of either normal $^{9}$ or delayed ${ }^{4}$ gastric emptying in functional dyspepsia. We have, however, recently described abnormal intragastric distribution of ingested food in dysmotility like dyspeptic patients and found an increased transfer of intraluminal contents from the fundus to the antrum even when overall gastric emptying was normal. ${ }^{28}$ The results of this study now suggest that the cause of such intragastric food maldistribution may be impaired fundal relaxation.

In conclusion, our results show that dysmotility like functional dyspepsia patients with postprandial bloating symptoms show, defective gastric accommodation both to distension and to food, and a lower threshold for the onset of abdominal discomfort. These results, which parallel those found in a group of postvagotomy patients with similar symptoms 
suggest a common underlying neural defect of vagally mediated pathways. The precise nature of this defect in the dyspeptic patients remains to be determined, however.

The authors are indebted to Mrs J Young for the assistance in preparing the manuscript. Part of this study was presented at preparing the manuscript. Part of this study was presented at the American Gastroenterological Meeting held in San Gastroenterology 1992; 102: A528.

Dr Troncon was the recipient of a fellowship grant from a covenant between the University of Sao Paulo, Brazil and the Interamerican Development Bank.

1 Talley NJ, Phillips SF. Non-ulcer dyspepsia: potential causes and pathophysiology. Ann Intern Med 1988; 108: 865-79.

2 Colin-Jones DG, Bloom B, Bodemar G, Crean G, Freston J, Gugler R, et al. Management of dyspepsia: report of a working party. Lancet 1988; i: 576-9.

3 You CH, Lee KY, Chey WY, Menguy R. Electrogastrographic study of patients with unexplained nausea bloating and vomiting. Gastroenterology 1980; 79: 311-4

4 Rees WDW, Miller LJ, Malagelada JR. Dyspepsia, antral motor dysfunction, and gastric stasis of solids. Gastroenterology 1980; 78: 360-5.

5 Corinaldesi R, Stanghellini V, Raiti C, Rea E, Salgemimi R, Barbara L. Effect of chronic administration of cisapride on gastric emptying of a solid meal and on dyspeptic on gastric emptying of a solid meal and on dyspeptic symptoms in patien

6 Malagelada JR, Stanghellini V. Manometric evaluation of functional upper gut symptoms. Gastroenterology 1985; 88: $1223-31$.

7 Bassotti G, Pelli MA, Morelli A. Duodenojejunal motor activity in patients with chronic dyspeptic symptoms. f Clin Gastroenterol 1990; 12: 17-21.

8 Malagelada JR. Gastrointestinal motor disturbances in functional dyspepsia. Scand 7 Gastroenterol 1991; 26 (suppl 182): 29-32.

9 Talley NJ, Shuter B, McCrudden G, Jones M, Hosch LR, Piper DW. Lack of association between gastric emptying of solids and symptoms in non-ulcer dyspepsia. $\mathcal{F}$ Clin Gastroenterol 1989; 11: 625-30.

10 Meyer JH. Chronic morbidity after ulcer surgery. In: Sleisenger $\mathrm{MH}$, Fordtran JS, eds. Gastrointestinal disease. Philadelphia: WB Saunders, 1989: 962-90.

11 Jahnberg T, Martinsson J, Hulten L, Fasth S. Dynamic gastric response to expansion before and after vagotomy. Scand $\mathcal{F}$ Gastroenterol 1975; 10: 593-8.

12 Ahluwalia NK, Thompson DG, Barlow J, Troncon LEA, Hollis S. Relaxation responses of the human proximal stomach to distension during fasting and after food. $A m \mathcal{F}$ Physiol 1994; 267: G166-72.
13 Siegel S. Non-parametric statistics for the behavioural sciences. New York: McGraw-Hill, 1956.

14 Malagelada JR, Azpiroz F. Determinants of gastric emptying and transit in the small intestine. In: Schultz SG, ed. Handbook of Physiology. Section G, Vol 1, part 2. Handbook of Physiology. Section G, Vol 1, part 2.
Bethesda: American Physiological Society, 1989: Bethesda:

15 Azpiroz F, Malagelada JR. Vagally mediated gastric relaxation induced by intestinal nutrients. Am F Physiol 1986; 251: G727-35

16 Bradette M, Pare P, Douville P, Morin A. Visceral perception in health and functional dyspepsia. Crossover study of gastric distension with placebo and domperidone. Dig Dis Sci 1991; 36: 52-8.

17 Lehman A, Dederding JP, Flourie B, Franchisseur C, Ramboud JC, Jian R. Abnormal perception of visceral pain in response to gastric distension in chronic idiopathic pain in response to gastric distension in chrom

18 Mearin F, Cucala M, Azpiroz F, Malagelada JR. The origin of symptoms on the brain-gut axis in functional dyspepsia. Gastroenterology 1991; 101: 999-1006.

19 Jahnberg T, Abrahamsson N, Jansson G, Martinson J. Gastric relaxatory response to feeding before and after vagotomy. Scand $\mathcal{F}$ Gastroenterol 1977; 12: 225-8.

20 Desai KM, Sessa W, Vane JR. Involvement nitric oxide in the reflex relaxation of the stomach to accommodate food or fluid. Nature 1991; 351: 477-9.

21 Nyren O. Secretory abnormalities in functional dyspepsia. Scand f Gastroenterol 1991; 26 (suppl 182): 25-8.

22 Nyren O, Adam HO, Bergstrom R, Gustavsson S, Loof L, Lundqvist G. Basal and food-stimulated levels of gastrin and pancreatic polypeptide in non-ulcer dyspepsia gastrin and pancreatic polypeptide in non-ulcer dyspepsia and $41-7$.

23 Oliveira RB, Troncon LEA, Meneghelli UG, Padovan W, Dantas RO, Godoy RA. Impaired gastric accommodation to distension and rapid gastric emptying in patients with Chagas disease. Dig Dis Sci 1980; 25: 790-4.

24 Aune $S$. Intragastric pressure after vagotomy in man. Scand $f$ Gastroenterol 1969; 4: 447-52.

25 Troncon LEA, Thompson DG, Fairbain I, Alhuwalia NK, Barlow J, Heggie LJ. Gastric fundal relaxation is modulated by lipids and osmolarity but no caloric composition. Gastroenterology 1992; 102: A528.

26 Notivol R, Mearin F, Azpiroz F, Malagelada JR. Epigastric symptoms are elicited by selective stimulation of 'in series' and 'in parallel' gastric mechanoreceptors. series' and 'in parallel' gas

27 Wilbur B, Kelly K. Effect of proximal gastric, complete gastric and truncal vagotomy on canine gastric electrical activity, motility and emptying. Ann Surg 1973; 178: 295-302.

28 Troncon LEA, Bennett RJM, Ahluwalia NK, Thompson DG. Abnormal intragastric distribution of food during gastric emptying in functional dyspepsia. Gut 1994; 35: $327-32$ 